\title{
Essential Contestability and Evaluation ${ }^{* \dagger}$
}

\author{
Pekka Väyrynen \\ University of Leeds
}

\section{Introduction}

Imagine widespread consensus regarding the good and the bad, the right and the wrong, the just and the unjust, and the like. You are likely to be imagining a utopia. In the actual world, substantive disagreement concerning how these moral concepts are properly applied is the rule rather than the exception. Thus it is often said, following W. B. Gallie, that evaluative and normative concepts are "essentially contestable" - their proper usage or application characteristically admits of substantive disagreement. $^{1}$

A massive range of terms and concepts have been labeled as essentially contestable. ${ }^{2}$ The notion is used widely in political and legal theory

*Thanks to audiences at Birkbeck College, University of East Anglia, University of Edinburgh, University of Kent, and the Values and Context workshop at University of Lisbon, as well as an associate editor and two anonymous referees for this journal, for helpful comments and suggestions.

${ }^{\top}$ This is a preprint of an article whose final and definitive form will be published in the Australasian Journal of Philosophy; the Australasian Journal of Philosophy is available online at: http://www.tandf .co.uk/journals/.

${ }^{1}$ I am taking a slight liberty here. Gallie (1956) speaks of essentially contested concepts. But the modalized notion of essential contestability has greater philosophical interest. Regarding notation, I'll use small caps to denote concepts and italics both to denote words and sentences and for occasional emphasis. Double quotes will be used in the many loose ways that quotation marks can be used, such as scare quotes or to mention a terminological expression and use it in the same breath.

${ }^{2}$ A Google Scholar search for "essentially contested concept" yields about 184,000 results, including concepts like STAKEHOLDER, MEDICINE, and SUSTAINABLE DEVELOPMENT. 
as a methodological framework for analyzing disagreements regarding the proper usage of political and legal concepts like DEMOCRACY, FREEDOM, SECURITY, GENOCIDE, HATE CRIME, and many more. ${ }^{3}$ The notion is also invoked frequently in applied ethics and political philosophy in debates concerning how to define concepts which pick out morally significant categories but over which there is persistent disagreement, such as COERCION, RAPE, and PERSONHOOD. ${ }^{4}$ Given how widely essential contestability gets invoked, it is important to understand what the notion is, how it works, and whether it really is useful.

What is the philosophical significance of essential contestability? It is widely taken to pervade the evaluative domain. How significant that would be depends on what exactly the essential contestability of all the major evaluative concepts would tell us about them. (I'll return to this.) But many people think further that essential contestability tells us something important about the evaluative in particular (though the details vary). ${ }^{5}$ For instance, it is far from clear what makes a term or concept an "evaluative" one. Although it is plausibly sufficient for a concept $\mathrm{C}$ to

\footnotetext{
${ }^{3}$ See Collier et al. (2006) for an overview of the framework's use in political theory. In a discussion of whether THE RULE OF LAW is essentially contestable, Waldron lists over 40 concepts that have been labeled as essentially contested in the Westlaw database (Waldron 2002: 149).

${ }^{4}$ See Rhodes (2000), Reitan (2001), and Gibson (2004). (If PERson isn't an evaluative concept, it'll add to the list of non-evaluative essentially contestable concepts in §3.)

${ }^{5}$ An explicit instance is Roberts (2013: 89-90). Wiggins (1998) invokes essential contestability repeatedly in the papers collected in the volume, and in one ("A Sensible Subjectivism?") he describes essential contestability as a central feature of evaluative language (Wiggins 1998: 198-9, 207). Dancy claims that there is "strong pressure to admit that the natural and the essentially contestable are incompatible" and the context shows that he assimilates the natural and the non-evaluative (Dancy 1995: 273). Other discussions that imply that essential contestability is an important constituent of evaluativeness include Mason (1990) and Reitan (2001). Most often the idea is implicit, however. Most of the work invoking the notion of essential contestability asks whether or not some concept $\mathrm{c}$ is essentially contestable and then defends the author's answer by arguing that $\mathrm{c}$ maps (or fails to map) onto Gallie's original characterization of essentially contestable concepts, assuming all along that $\mathrm{c}$ is evaluative largely without question. (I'll introduce Gallie's characterization in §2.) Much the same goes for discussions of essential contestability itself, including Gray (1977), Kekes (1977), Hurley (1989), and Collier et al. (2006). Gallie's characterization is also the typical context of remarks to the effect that essential contestability is a "notable" feature of moral concepts (Lukes 1974a: 177) or a feature concepts have "because" they are political (Grafstein 1988: 26). A related point is that some social scientists regard the appeal to essential contesta-
} 
be evaluative that propositions of the form $x$ is $C$ analytically entail reasons for (or against) certain actions or attitudes, this condition might not be necessary. If one thinks that good with kids or elegant, for instance, would be evaluative terms even if they didn't analytically entail reasons for action, then one should find some other criterion. What suggests essential contestability as one potential factor in demarcating evaluative and normative concepts from concepts that are neither is that ascriptions of praiseworthiness or some other positive standing with respect to some standard might characteristically admit of substantive disagreement even if those ascriptions weren't analytically connected to reasons for action.

The main aim of this paper is negative. I'll argue that the notion of essential contestability offers no deep illumination of the evaluative in particular. (For brevity I'll use the term "evaluative" to cover both the normative and the evaluative.) That is because terms or concepts can satisfy the central characteristics of essential contestability without being evaluative. The most immediate upshot of this argument will be that essential contestability isn't sufficient for a term or concept to be evaluative in meaning. Those who think that essential contestability can help to demarcate evaluative terms and concepts from the non-evaluative might be willing to grant as much (Roberts 2013: 89). But my argument will show further that the central features of essential contestability are exemplified by many evaluative and non-evaluative terms equally in virtue of more general features which they share (such as multidimensionality) and which have nothing in particular to do with being evaluative. ${ }^{6}$ So if all major evaluative terms and concepts are essentially contestable, this will tell us that they share some of their significant features with various non-evaluative terms and concepts. But essential contestability will be at best a non-distinctive and relatively weak necessary condition for a term bility as reflecting a recognition that social science research is routinely not value free (Collier et al. 2006).

${ }^{6}$ I gave a very short argument for this conclusion in Väyrynen (2013: 211-13). This paper improves upon and supersedes that argument. 
or concept to be evaluative and won't tell us anything significant about the evaluative in particular. $^{7}$

I won't attempt a positive account of essential contestability, owing to certain broader implications of my argument. Essential contestability may not be a unified phenomenon. I'll argue that its central characteristics may arise in many different ways, corresponding to different kinds of disagreement. ( $\S 3-4$ will focus on one of these; I'll touch on others in §5.) If its central characteristics cut across different types of disagreement, then its value in understanding moral, political, and legal disagreements may be at best limited. Even if essential contestability still turned out to be useful for analyzing these disagreements, that wouldn't be because they are evaluative disagreements, but for some more general reasons. Along the way I'll also highlight some mechanisms for resolving some of the sort of disputes that are supposed to be characteristic of essential contestability. ${ }^{8}$ So if disputes over the correct application of central moral, political, and legal terms and concepts really are as intractable as they are sometimes taken to be, their intractability won't be fully explained by essential contestability. ${ }^{9}$

\section{What Is Essential Contestability?}

In the discussion that introduced the notion, W. B. Gallie characterizes essentially contestable concepts (ECCs) as follows:

\footnotetext{
${ }^{7}$ It is a good question whether essential contestability is necessary for a term or concept to be evaluative. (Consider examples like is good or is not good.) But this demarcation problem isn't my topic here.

${ }^{8}$ My discussion will also help to straighten out questionable interpretations of essential contestability in political and legal theory. Waldron (2002: 148-9) complains that in the law review literature "essentially contested" has come to mean something like "very hotly contested, with no resolution in sight". But the "temperature" of the disputes will be neither here nor there. Sometimes essential contestability is understood as requiring that the relevant disputes be in principle unresolvable, which makes it hard to see how any genuine "contest" could be said to be occurring (Gray 1983: 96). But my argument will indicate why essential contestability doesn't imply in-principle unresolvability.

${ }^{9}$ For a very different argument to the same effect, see Mason (1990).
} 
(E1) ECCs are "appraisive", in that they ascribe some kind of "valued achievement".

(E2) ECCs have an "internally complex character".

(E3) This internally complex character admits of a wide range of descriptions depending on the relative significance attributed to the contributions of the component features.

(E4) Such descriptions are "open" in character, in that they admit of considerable modification in different circumstances in a way that cannot be prescribed or predicted in advance. ${ }^{10}$

Subsequent discussions largely adopt these as the central defining features of essential contestability; I'll clarify them further as and when needed. ${ }^{11}$ Gallie gives various examples to illustrate this complex notion. Democracy, for instance has multiple internal components, including perhaps majority rule, self-government, and the equal right of all citizens to seek political office (E2) (Gallie 1956: 184-5). ${ }^{12}$ What count as instances of these factors can be conceived of, and their contributions weighted, in different ways (E3). And the targets that a political system must at minimum achieve regarding majority rule and the other factors to count as democratic can be raised or lowered as circumstances change, giving the notion the kind of openness at issue in (E4) (Gallie 1956: 186).

\footnotetext{
${ }^{10}$ See Gallie (1956: 171-2). Gallie suggests two further features, but it is less clear whether they are necessary for essential contestability. The first is that each party to a dispute about the correct application of some ECC must recognize that its own use is contestable by other parties and each party must have some appreciation of the different criteria that others take to govern its application (Gallie 1956: 172). The second is that such a dispute involves appeals to exemplary instances of the concept such that the disputants claim to be extrapolating the relationships among the component features which are displayed by the exemplar(s) (Gallie 1956: 176-7, 190). These two features are controversial but will require little role in my discussion.

${ }^{11}$ See e.g. Gray (1977), Kekes (1977), Swanton (1985), Hurley (1989: 46-8), Reitan (2001), Waldron (2002), Gibson (2004), and Roberts (2013: 89-90). Occasional worries about or departures from these features are usefully surveyed in Collier et al. (2006).

${ }^{12}$ Just what qualifies as the kind of internal complexity that Gallie has in mind is unclear. But merely conjunctive and disjunctive structures clearly seem not to qualify.
} 
The question I raised at the outset is whether the notion of essential contestability can help to demarcate the evaluative from the nonevaluative. So consider (E1). If we simply stipulate that a concept can be essentially contestable only if it is "appraisive", then essential contestability isn't cut out for the job. But Gallie doesn't merely stipulate this. He takes (E2)-(E4) to secure (E1). For he says that "my suspicion is that no purely naturalistic concept will be found conforming" to (E2)-(E4), and it is clear from the context that he is using "naturalistic" to mean "nonevaluative". ${ }^{13}$ What I'll argue is that many terms or concepts that satisfy (E2)-(E4) aren't evaluative in the sort of sense that (E1) is reasonably taken to have.

This calls for clarification. Almost any word is capable of being used evaluatively. For instance, describing a house's orientation as one that maximizes direct sunlight would normally be interpreted as implying or inviting positive appraisal. ${ }^{14}$ Real estate agents make a lot out of "south facing windows" in the northern hemisphere and "north facing windows" in the southern hemisphere. Given what people normally desire, these descriptions tend to carry the conversational implicature (albeit one rejected by painters who want to avoid having direct sunlight shine into their studios) that the house is to be regarded favorably in the respect at hand. So although maximizing direct sunlight isn't usually thought of as an evaluative term, it can be used for evaluative purposes. Similar effects can be achieved also through intonation; for instance, I may call a chocolate "fruity" in a tone of dislike.

By "appraisive" Gallie must thus mean something like "semantically evaluative". ${ }^{15}$ So what I'll argue is that terms or concepts that satisfy

\footnotetext{
${ }^{13}$ See Gallie (1956: 174). Gallie is clearly not giving arguments against ethical naturalism in his discussion. In focusing on whether (E2)-(E4) secure (E1), I am not claiming that Gallie's own main concerns lie with the sorts of questions about evaluative language and concepts which exercise contemporary metaethicists or philosophers of language. Gallie seems at least equally, if not more, concerned with the notions of tradition and true succession in a tradition; see Ruben (2010). I am addressing the kind of use to which essential contestability has been subsequently put by many others.

${ }^{14}$ This example is adapted from Blackburn (1992: 287).

${ }^{15}$ Here "semantic" may be understood broadly to include not only the sort of meaning that feeds into compositional semantics but also such further semantic properties as
} 
(E2)-(E4) needn't be semantically evaluative. It needn't be analytic of such terms concepts that they ascribe some kind of valued achievement, or their extension is determined by standards whose satisfaction entails positive (or negative) appraisal, or the like. ${ }^{16}$ My strategy will be to argue that (E2)-(E4) can be explained by more general factors that have nothing in particular to do with being evaluative in this sense. (As I'll discuss later, I claim that this is one way for (E2)-(E4) to arise, not the only way.) First in §3 I'll give one recipe for constructing counterexamples to the claim that (E2)-(E4) secure (E1), illustrate it with examples, and describe some of its variations. Then in $\S 4$ I'll discuss what the failure of (E2)-(E4) to secure (E1) tells us about the sort of disputes that are supposed to be characteristic of essential contestability and how that in turn bears on our understanding of evaluative disagreement.

\section{Essential Contestability and Multidimensionality}

I'll begin with a recipe for constructing counterexamples to the claim that (E2)-(E4) secure (E1) which has more ingredients than I strictly need for my purposes. My rationale is that this recipe makes for a particularly clear illustration of one general conceptual structure that generates (E2)-(E4) but is exemplified also by semantically non-evaluative expressions. Here is the recipe. Take a gradable expression (one that measures a quality which can be had more or less of) which is multidimensional and whose dimensions admit of different relative weightings in the interpretation of the expression; this will secure (E2) and (E3), respectively. When such a term is context-sensitive, it will be particularly clear that the relative weightings may be modified in ways that cannot be predicted

conventional implicature and semantic presupposition. I won't comment separately on the last two.

${ }^{16}$ This is the sort of notion of evaluation that is of primary interest to moral, political, and legal philosophy. It is to be distinguished from a weaker notion found in linguistics, according to which any term whose extension is set by a standard (of whatever sort) is evaluative. Terms like tall and heavy count as evaluative in the weaker sense (something counts as tall if it exceeds the contextually determined standard of height) but not the stronger. 
or prescribed in advance; this will secure (E4). ${ }^{17}$ My claim will then be that such a term needn't be (although of course it can be) semantically evaluative.

A concrete illustration of this counterexample recipe will be useful. I believe that the term painful and its comparative more painful than can be used to construct fairly simple examples that help to make the structure of my argument perspicuous. (I'll address some concerns about the example and offer others once we have the general structure on the table.) When eventualities are assessed in terms of their painfulness, what matters? At least the intensity of pain and its duration matter. Determining what it means to say that something is painful, or that it is more painful than something else, requires also some way of binding these dimensions together. So the multidimensionality of painful gives it the internal complexity that is required by (E2).

What about (E3)? Consider the following scenario:

Painful Day: Day 1 has a longer duration of pain of lower intensity. Day 2 has short durations of pain of higher intensity.

Which day is more painful of the two? Well, that depends on how intensity and duration are weighted. It is perfectly coherent to give these dimensions different weightings and to disagree over the appropriate weighting, and this is robust across a wide range of differences in intensity and duration between Day 1 and Day 2 . These points about the comparative more painful than go also for the positive form painful. In some contexts duration may matter little to what counts as painful, sometimes it may be claimed to matter quite a bit, and so on. The same points will hold equally for variants where what is assessed for painfulness aren't

\footnotetext{
${ }^{17}$ The framework I'll use in articulating the basic counterexample recipe is semantic contextualism. This isn't the only possible framework. I adopt contextualism over semantic relativism, for instance, because it isn't clear to me how exactly relativists treat multidimensional gradable expressions. I have some hope that the failure of (E2)-(E4) to secure (E1) will be robust across different frameworks. For instance, toward the end of this section I'll explain why context-sensitivity and gradability (although helpful for illustrative purposes) aren't essential.
} 
days but, for instance, ailments. So the internal complexity exemplified by painful has the kind of "multiple describability" or "combinatorial tolerance" that is required by (E3).

Also (E4) seems secure. The combinatorial function that binds the dimensions into a measure of painfulness may vary with context in a way that cannot be prescribed or predicted in advance. There is no saying in advance, for instance, what considerations novel circumstances might introduce to modify previous weightings of intensity and duration. So the application of painful has the kind of openness that is required by (E4). This point stands irrespective of how we analyze the dimension binding operation that determines the interpretation of multidimensional expressions. ${ }^{18}$ It is enough for my purposes that in practice we somehow reliably succeed in assigning these expressions a determinate enough content, and therefore somehow manage to bind the dimensions together (Glanzberg 2007: 26).

So both the positive and the comparative form of painful satisfy (E2)(E4). My claim is that they fail (E1): painful and more painful than aren't semantically evaluative expressions. If that is right, then what we have here is an illustration of the general point that (E2)-(E4) can be explained as a function of factors that have nothing in particular to do with being evaluative. (In this counterexample recipe these factors are features of certain multidimensional gradable expressions.) The illustration would also be like paradigmatic ECCs in the respect that disputes about what counts as painful, or more painful than something else, can often be very much worth having. In §4 I'll discuss whether this recipe for generating (E2)-(E4) from factors that have nothing in particular to do with being evaluative yields a plausible account of the sort of disputes that ECCs are supposed characteristically to admit. But first I'll address objections to my argument so far.

One might object that painful cannot provide an example of a term that meets (E2)-(E4) but not (E1), on the grounds that painful is in fact a

\footnotetext{
${ }^{18}$ For discussion, see e.g. Benbaji (2009) and Sassoon (2013: 338-40).
} 
semantically evaluative term. No doubt some of the many ways we talk of pain come close to the evaluative, as when we talk of pains as experiences their subjects would prefer to avoid. The official scientific definition of pain as "an unpleasant sensory and emotional experience associated with actual or potential tissue damage, or described in terms of such damage" ascribes to pain an affective aspect (IASP 1994: 209). My example above will go through under this definition, but the definition is silent on whether the affective aspect of pain is to be explicated in evaluative terms. That is what evaluative theories of pain do, for instance by treating bodily pains as felt evaluations or as consisting in an occurrent phenomenal state plus a simultaneous evaluation of that state. ${ }^{19}$ But it is one thing to propose an evaluative theory of pain, quite another to say that the theory also provides the correct semantics of the term pain. Someone who denies that a painful experience is thereby bad may well be mistaken but needn't be conceptually confused or semantically incompetent. The sorts of evaluative claims about pain that most of us accept can also be captured perfectly well without treating painful as semantically evaluative. Pain can be a reason-giving or bad-making feature, even necessarily so, without this being analytic of painful or otherwise making painful itself semantically evaluative. ${ }^{20}$ Pain can even be identical with badness without there being any semantic or conceptual connection between painful and bad. In short: the objection that painful is a semantically evaluative term is poorly motivated. ${ }^{21}$

Other sorts of examples of non-evaluative terms that satisfy (E2)-(E4) are also available. ${ }^{22}$ One set of examples comes from debates in biology about what counts as a member of species, and even what counts as a species. Such disputes often invoke multiple criteria that can be

\footnotetext{
${ }^{19}$ See, respectively, Helm (2002) and Nelkin (1994).

${ }^{20}$ Moral philosophers who suggest that pain is itself evaluative often turn out to have this sort of claim in mind.

${ }^{21}$ Elsewhere (Väyrynen 2013) I argue at length that not even paradigmatic "thick" terms and concepts, such as cruel, selfish, and courageous, are semantically evaluative in the relevant sense.

${ }^{22}$ Thanks to an anonymous referee for suggesting the examples to follow.
} 
legitimately weighted in different ways, and thanks to wonders of evolution these matters cannot be prescribed in advance. ${ }^{23}$ The point will be straightforward if species are cluster kinds. But it applies also if species membership is a matter of being derived from a common ancestor: two populations with the same ancestry will count as separate species given a sufficiently clear divergence between them, and disputes about the proper measures of such divergence exemplify (E2)-(E4). Already the fact that species exhibit both stable similarities and stable variations will help to secure (E2)-(E4). Coyotes and wolves can interbreed but we count them as different species, whereas many organisms are counted as belonging to the same species although they reproduce asexually. Here, too, how various criteria are weighted in different cases and what criteria may become relevant seems in principle open to contest even if in practice contestation is rare. Structurally similar examples arise, among other places, in economics, where the standard textbook definition of money lists three functions: medium of exchange, unit of account, and store of value. These functions are independent, may conflict, and are open to being weighted differently in disputes about whether something counts as money. Expressions like same species as and money aren't semantically evaluative in the relevant sense. So they can serve as other counterexamples to the claim that (E2)-(E4) secure (E1).

A different objection would be that the examples I use to illustrate the counterexample recipe aren't cut from the same formal cloth as Gallie's examples, such as democracy, work of art, the champions, and Christian doctrine (Gallie 1956: 168). These examples aren't obviously contextsensitive and only some seem gradable. Why then think that what I say about my illustrative examples bears deeply on the notion of essential contestability that has interested moral, political, and legal theorists?

This objection isn't persuasive for two reasons. One is that some of Gallie's own examples (such as just) are context-sensitive terms. The other is that for the sake of clarity my initial counterexample recipe has

\footnotetext{
${ }^{23}$ Various accounts of biological species can be found in Wilson (1999).
} 
more ingredients than it needs. While money seems gradable, it isn't context-sensitive, and species concepts aren't obviously gradable even if some of their dimensions are. The crucial feature is multidimensionality.

Multidimensionality is a widespread feature of evaluative terms. For instance, a good philosopher measures things along such dimensions as rigor, clarity, originality, creativity, and probably more besides; these dimensions and their relative significance admit of a wide range of descriptions and disagreement; and such descriptions are open-ended. Much the same can be said about courageous, morally good, and the like. Gallie himself understands democracy as having multiple dimensions such as majority rule, self-government, and the equal right of all citizens to seek political office. How these dimensions are to be weighted seems openended and disputable irrespective of semantic context-sensitivity.

Broadly the same analytical framework that I have put to work in this section remains applicable here. ECCs seem to exemplify the same kind of internal complexity as characterizes multidimensional expressions generally. For instance, their dimensions allow disaggregation in the way multidimensional expressions do in general. We can say that someone is intelligent in mathematics though not with social relationships, healthy except for high cholesterol, or healthy with respect to sexually transmitted diseases (Sassoon 2013: 337-8). This way of representing dimensions of predicates as predicates in their own right is equally possible with ECCs. We can say that a nation is democratic except for the right of all citizens to seek political office or particularly democratic with respect to majority rule, and that a distribution is fair regarding equality of opportunity though not regarding desert. (The possibility of disaggregation doesn't mean that the aggregate concept is a mongrel; consider DEMOCRACY.) Context-sensitivity is inessential because context-invariant multidimensional expressions can be treated as limiting cases where the weighting is always the same, and it is disputed what this weighting is. And as I'll explain in $\S 4$, possibility of disputes about the relevant dimensions is independent of gradability. 
My argument in this section is robust across various more specific interpretations of Gallie's conditions (E2)-(E4). For instance, some writers characterize (E4) as claiming that the relevant disputes "cannot be settled by appeal to empirical evidence, linguistic usage, or the canons of logic alone" (Gray 1977: 344). Linguistic usage and canons of logic do little to constrain different relative weightings that intensity and duration may be given in interpreting painful, and disputes over the weightings may remain even given all the factual information about intensity, duration, the pain tolerance of the subjects in question, and so on. (The same goes for many disputes about whether two organisms belong to the same species.)

My argument can also accommodate a further feature of Gallie's examples, namely that they involve an exemplar which the disputants acknowledge as authoritative and which provides a common core that anchors a shared concept. (Gallie's idea is that the disputants' disagreement over the correct application of the concept results from extrapolating different views of what relationship among the component features of the concept the exemplar exemplifies.) In the case of painful the likely exemplars would rate high on both the intensity and the duration of the pain. The question of which patient has had a more painful day (or ailment) would then be open to disagreement over which patient is a closer match with the exemplars whenever they rate differentially on one or the other dimension. Such a dispute would again reflect different relative weightings of intensity and duration.

I have argued that there are terms which satisfy (E2)-(E4) irrespective of whether they are semantically evaluative. (E2)-(E4) are explicable as a function of general features of certain types of multidimensional expressions. So if all major evaluative concepts were essentially contestable, that might mean that they are all multidimensional. That might be significant, but the upshot of my argument is that it wouldn't tell us anything distinctive about the evaluative in particular.

In fact it doesn't matter to my argument whether (E2)-(E4) can also arise from features other than multidimensionality or be exemplified by 
other types of terms. My counterexample strategy nonetheless looks robust. Many multidimensional gradable terms exemplify (E2)-(E4) in both their positive and comparative form. Nor does my explanation of (E2)(E4) collapse essential contestability into vagueness. For even if multidimensional gradable terms are vague, their vagueness plays no crucial role in the explanation. ${ }^{24}$

This framework for explaining (E2)-(E4) also avoids difficulties with the common explication of essential contestability in terms of competing "conceptions" of a shared concept. ${ }^{25}$ There are at least two different concept-conception distinctions. One of them treats a conception as something like a proposed real definition of the property ascribed by the concept. The other treats a conception as an account of the features which "give rise" to this property (the "right-making" features in the case of right, and so on). Both distinctions allow substantive disagreements between competing conceptions. So which is supposed to be the sort that characterizes essential contestability? Each concept-conception distinction is also hard to make precise without taking a stand on controversial issues like the nature of concepts. For we need to say something about what information is conceptually encoded and what information is left over to conceptions before we can use the distinction to explicate essential contestability. My proposed treatment of (E2)-(E4) sidesteps these complications.

\footnotetext{
${ }^{24}$ Vagueness might well not account for essential contestability in full generality. For instance, essential contestability might be taken to allow some disputes even at the core of a concept, not just at its borderlines or penumbra; see e.g. Waldron (2002: 149). Essential contestability might be distinguished from the context-sensitivity of many onedimensional gradable adjectives in the same way. Whatever disputes are possible concerning tall or young, one thing not open to dispute is that tall concerns (ascending) height and young concerns (descending) age.

${ }^{25}$ See e.g. Rawls (1971: 5-6), Lukes (1974b: 26-7), Dworkin (1978: 134-5), and Roberts (2013: 90). For a different criticism of the concept-conception account of essential contestability, see Swanton (1985).
} 


\section{Essential Contestability and Metasemantic Disputes}

If many multidimensional gradable expressions satisfy (E2)-(E4), what does this imply regarding the sorts of disputes that ECCs are supposed characteristically to admit? The most immediate upshot is that these instances of essential contestability don't require speakers who disagree with one another to assert and deny inconsistent contents when they utter sentences to the effect that something is (or isn't) democratic, just, more painful than something else, and so on. The disputes described in $\S 3$ regarding what is painful involve a metasemantic dispute. As I use the term here, metasemantics concerns how content (relative to context) is determined in the first place, on the basis of which contextual factors and computational rules operating on the term's linguistically encoded meaning. ${ }^{26}$ I'll now characterize the relevant kind of metasemantic disputes and argue that at least one type of dispute that ECCs characteristically admit (and therefore one type of evaluative dispute) can be fruitfully understood as metasemantic in that way. (Again painful will provide an instructive example, so it is worth noting that the use to which I put it here cuts across the issue whether painful is semantically evaluative.)

As a context-sensitive term, painful lacks semantic content unless and until parameters such as the relevant dimensions and their relative weightings are somehow fixed by context. There is room for debate here, but the metasemantics of gradable expressions seems to be "indirect". The relevant contextual parameters seem not to be fixed solely by any single feature of the context (whether a speaker's intention or a publicly observable gesture), but rather by many contributing factors that sometimes conflict. ${ }^{27}$ Factors that may in general be thought eligible to play a

\footnotetext{
${ }^{26} \mathrm{My}$ discussion of metasemantics draws on Glanzberg (2007) and Kennedy (2007). In the cases of interest to me, linguistically encoded meaning can be understood as a function from contexts to contents à la Kaplan's notion of "character" (Kaplan 1989).

${ }^{27}$ Of course speaker intentions sometimes play a significant role in setting contextual parameters. But as Michael Glanzberg points out, if we are at a conference on international development, the standard for richness doesn't suddenly drop from having (say) a billion disposable dollars if I insist that having a thousand dollars counts as rich or have idiosyncratic beliefs about money which could lead me to believe that having a
} 
metasemantic role include what is salient in the environment, speakers' and hearers' intentions, coordinating intentions, the conventional meanings of the expressions involved, shared presuppositions and other features of discourse structure, and general principles governing context.

Above I claimed that many multidimensional gradable expressions exemplify the central features of essential contestability irrespective of whether they are semantically evaluative. If the metasemantics of the relevant expressions is indirect, this opens up room for complex disputes about what the interpretation of such an expression is or should be, based on different views about what the values of some contextual parameters are (such as the threshold for counting as painful or the relative weighting of the different dimensions on which the threshold depends), what factors play a role in setting those values, what contributions those factors make, and how those contributions combine to determine content. But this is to say that multidimensional gradable expressions will exhibit (E2)-(E4) when they have an indirect metasemantics, which further supports my argument above. The suggestion I want now to make plausible is that at least one type of dispute admitted by terms that satisfy (E2)(E4) is fruitfully modeled as metasemantic in this sense. I'll explain why metasemantic disputes can be just as worth having as the disputes that ECCs are supposed characteristically to admit. I'll also say a bit about how these disputes sometimes get resolved and when they resist resolution.

Although metasemantic disputes concern word use, they can be worth having. Disputes about word use needn't be merely verbal or terminological, even if this is one of their features. Even if a term isn't itself semantically evaluative, what is at issue when its interpretation is disputed can have great normative import. If we run short on pain relief medication, we may need to decide which patients to help first. In such cases it can matter very much which ailments count as more painful than others. These verdicts will depend on how the semantic value of painful for the context is determined (how intensity and duration are weighted,

thousand dollars is being rich for this context. These factors don't change the content of my claims about who is rich in this discourse setting. See Glanzberg (2007: 26). 
and so on), and disputes about that fall under metasemantics as I have characterized it.

It can also make sense to continue to engage in these disputes. Each side in disputes concerning what the relevant dimensions are and how they are to be weighted can normally be backed up by substantive considerations. Consider this case:

Two Ailments: Ailment 1 involves short peaks of intense pain;

Ailment 2 involves pain that is slightly less intense but chronic.

One might agree that Ailment 1 is bad but nonetheless prefer a weighting under which Ailment 2 comes out as more painful on the grounds that chronic conditions like Ailment 2 tend to have a more debilitating effect on the patient's life. (The question at issue might be, for instance, the patients' comfort.) Insofar as the considerations that can be used to back up different interpretations may vary as circumstances do, even non-evaluative multidimensional terms can have the kind of "open texture" that (E4) aims to characterize. Two Ailments also illustrates how evaluative factors can be eligible to play a metasemantic role even if the expression at hand isn't semantically evaluative. Factors that play a metasemantic role in determining content don't thereby end up in the content.

Even if terms that aren't semantically evaluative can manifest (E2)(E4), one might worry that their essential contestability is somehow derivative from semantically evaluative ECCs. Perhaps disputes about what counts as painful are worth engaging in only given some background of evaluative notions which are essentially contestable. There is a lot to say, but here I can only briefly explain why I find this worry unconvincing. Such an evaluative background might be necessary for a dispute to be worth engaging in without being necessary for the issue at stake to be contestable in the first place. (As I'll explain below, not all disputes over evaluative ECCs are worth engaging in.) So is it necessary for the possibility of a dispute? Although evaluative background factors may well play a metasemantic role in cases like Two Ailments, that is semantically optional 
unless a term already counts independently as semantically evaluative. ${ }^{28}$ It remains unclear in what other sense such an evaluative background is supposed to be non-optional for the possibility of a dispute.

Metasemantic disputes often get resolved. Even when we have different ideas about what counts as rich, or spicy, or tall for the context, plainly we often come to agree on the standard. If you call a curry spicy, I might say Nah, that curry isn't spicy at all! In many cases like this there presumably is no antecedently settled objective standard for spiciness which we are disputing. Rather we are negotiating what the standard is going to be, and the point of my utterance would be that we need to add more spice. ${ }^{29}$ (Perhaps we are in a cooking contest where only the fieriest stuff will impress.)

When speakers have different ideas about what dimensions to take into account or how to weight them in interpreting multidimensional expressions, it isn't always easy to tell whether the dispute concerns some antecedently settled objective facts or (more weakly) is to some extent guided or constrained by such facts. But sometimes negotiation seems to be an admissible mechanism for determining how (say) to weight the different dimensions. Regarding painful, we might come to agree on a contextual purpose like keeping pain below a certain threshold of intensity, so that things above this threshold will count as painful for that context. Or we might come to share background beliefs such that the intensity of pain is privileged over its duration in our assessments of painfulness or, at least, that the admissible range of weightings is tightly constrained. ${ }^{30}$

Even if metasemantic disputes often get resolved, this marks no difference in kind between non-evaluative multidimensional expressions and paradigmatic examples of ECCs. I'll mention three respects in which the two are parallel.

\footnotetext{
${ }^{28}$ I discuss the issues that arise here more fully in Väyrynen (2013: 173-6).

${ }^{29}$ I owe this kind of example to Plunkett and Sundell (forthcoming). They discuss more extensively than I have space to do here how the way we use words can matter greatly and why the corresponding metalinguistic disputes can be worth engaging in.

${ }^{30}$ The relevant sort of background agreement might concern, for instance, what is morally at stake in taking one thing to be more painful than another.
} 
First, among Gallie's original examples of ECCs, justice is a paradigmatic case of a term where even the property measured by the term is open to dispute. (The Rawls-Nozick debate over distributive justice might be one example of this.) But it would be a mistake to suppose that openness to such disputes is distinctive of evaluative terms. In some contexts we may dispute whether to bracket a dimension that we usually take into account in interpreting some non-evaluative term. For instance, duration might not always be relevant to what should count as painful. Or we might debate whether body mass index of some magnitude or some physical disability is relevant to what falls under sick in some context.

Second, the extent and depth of disputes about the relevant dimensions and their weighting seem to covary with what is at stake in the dispute in the same way irrespective of whether the expression in question is semantically evaluative. ${ }^{31}$ When a lot is at stake in what counts as cold in our shared office, we would expect that the dispute isn't easily resolvable. (Will I, a delicate creature, catch a cold that will keep me out of work at the busiest time of the year? Are you, with your robust constitution, going to get sweat rings that will negatively impress your date that evening?) When not very much is at stake in what dimension counts as the measure of distributive justice, we would expect the dispute to be quickly settled, or at least bracketed for the purposes at hand. (Perhaps our policy options compare in the same way when measured by their impact on equality of opportunity and on equality in income, so that continuing the dispute will make little practical difference in our collective decision making. ${ }^{32}$ ) This isn't to say that these disputes might not characteristically differ in their extent or depth depending on whether the terms of the dispute are evaluative or not. But such differences in degree are tangential to the issue at hand and perhaps explicable by cultural and social factors. Semantically evaluative terms tend to find their subject matter somewhere in the rich

\footnotetext{
${ }^{31}$ Plunkett and Sundell (forthcoming) defend the related point that whether metalinguistic disputes are worth having is independent of whether the competing claims are advanced via semantic or pragmatic mechanisms.

${ }^{32}$ Collier et al. (2006) discuss similarly how "practical closure" can limit the combinatorial tolerance and openness of ECCs.
} 
tapestry of individual and social concerns. (But again this isn't unique to evaluative terms; consider painful or perhaps even species.) It would then be no surprise if they commonly figured in disputes where a great deal is at stake.

Third, the sort of disputes that are characteristic of ECCs also sometimes get resolved, and sometimes this happens through metasemantic negotiation. In disputing what it takes to constrain policy making by considerations of distributive justice, we might come to agree what the relevant dimensions are or how they are to be weighted, and thereby to agree what counts as just for the purposes at hand. (Thus metalinguistic disputes can have great import in our collective decision making.) We might agree to focus on equality of opportunity over equality in income. Or we might agree to take both into account but prioritize equality of opportunity when the two conflict. ECCs have no immunity against ideology, but they become no less contestable if they happen to acquire a stable interpretation that isn't actually contested.

Acknowledging metasemantic negotiation as one mechanism for resolving disputes over the application of at least some ECCs doesn't require conventionalism about their subject matter. ${ }^{33}$ (Or at least not any more than the context-sensitivity of tall or heavy makes facts about what counts as tall or heavy conventional.) Here I can offer only a few quick reasons which are by no means exhaustive. The suggestion on the table is that negotiation is one (but not the only) mechanism that can be deployed in computing semantic value for the context from various contextual inputs. But it won't always be an appropriate mechanism. Sometimes we may be disputing an antecedently settled objective standard. Perhaps (whether as a result of agreement or antecedent fact) what falls under some moral term, for instance, is determined by the correct moral standards, whatever they are. In such cases facts about which particular things fall under the term will admit further dispute focused on what the correct standards are. Even when negotiation does play a dominant role in semantic interpreta-

\footnotetext{
${ }^{33}$ Thanks to an anonymous referee for raising this worry.
} 
tion, its output will be constrained by the various inputs from context as well as other possible mechanisms for resolving conflicts between these inputs. Contextual inputs can include various objective extra-linguistic facts in addition to what is salient in context, speaker and hearer intentions, shared presuppositions, and so on.

The results of metasemantic negotiation among conversational partners can also be substantively objectionable and open to dispute by external parties. This can happen equally well with distributively just, democratic, painful, or rich. Sometimes there may be very good reasons for regarding the duration of pain as a minor factor. In such cases (but perhaps not otherwise) a proposed interpretation of painful which weights duration heavily can be justifiably judged inferior. But if you and I agreed in discussing international development that having one thousand disposable dollars counts as rich or that countries with very limited citizen access to political office and influence to policy making count as democratic, our standards would be criticizable on the basis of all sorts of facts.

The fact that metasemantic disputes sometimes get resolved connects up with the issue whether the notion of essential contestability allows the competing interpretations of ECCs to be compared. Some writers worry that essential contestability invites some problematic kind of conceptual relativism (Gray 1977: 343). Others think that essential contestability allows some proposed interpretations to be judged better than others even if the best interpretation is open to contest (Swanton 1985; Mason 1990). Treating (E2)-(E4) as a function of how many multidimensional expressions in general work makes this issue more tractable because it helps us to articulate at least some of the various respects in which their proposed interpretations can be assessed, such as how these interpretations take into account various inputs from context, how they resolve conflicts between these factors, and so on. In line with my discussion in the previous paragraph, sometimes a proposed interpretation can count as superior, and even objectively so, depending on the question at issue and the facts about the context. Worries about relativism seem therefore unfounded at 
least in those instances of essential contestability which allow the kind of explanation I have sketched.

No doubt more could be said about the various relations between metasemantic disputes and the sort of disputes that seem characteristic of ECCs. But the differences that might matter here would seem to be differences in degree rather than kind, and explicable in terms of broader cultural and social factors. So it seems safe to conclude that at least some disputes of the sort that are supposed to be characteristic of ECCs are fruitfully modeled as metasemantic. Since multidimensional gradable expressions characteristically admit of metasemantic disputes, this would further support my earlier account of (E2)-(E4) as a function of how many such terms generally work.

\section{Conclusion}

I have argued that the central features of essential contestability laid out in (E2)-(E4) are a function (though not a unique function) of general features of a certain type of evaluative and non-evaluative terms. This is an instance of a general argument strategy: explaining some features that might be thought distinctive of evaluative terms and concepts by more general factors that have nothing in particular to do with evaluative. ${ }^{34}$

If even some disputes of the sort that are supposed to be characteristic of ECCs are metasemantic (or otherwise metalinguistic) and if evaluative terms and concepts are essentially contestable, then it follows that certain evaluative disputes are metasemantic (or otherwise metalinguistic). This would be important to moral philosophy. In conclusion I'll briefly explore how it would require us to refine our understanding of moral disagreement.

\footnotetext{
${ }^{34}$ I apply the same general strategy to certain other putatively demarcating features of the evaluative in Vayrynen (2013: chs. 7-8). One attempt to spell out what it is for a concept to be evaluative, according to which the possession of certain "marks" of the evaluative such as essential contestability is explained specifically by the fact that the concept is evaluative, can be found in Roberts (2013).
} 
What the argument I have given suggests is that disputes that we call moral disagreements may in fact involve several distinct types of dispute. Disputes about what counts as distributively just or morally right, for instance, may involve one or more of the following types (which are likely not exhaustive), in some or other combination:

(a) Disputes about what the content of the relevant expression for the context is or should be (the metasemantic disputes discussed in $\S 4$ ).

(b) Disputes about what the meaning of the expression is or should be in the first place (another type of metalinguistic dispute).

(c) Disputes about the nature or the "real definition" of the property which the expression ascribes (for instance, whether being morally right is identical or reducible to maximizing aggregate utility).

(d) Disputes about what features "make" things just or morally right or "ground" their justice or moral rightness.

Describing moral disagreements as disagreements about what is just, morally right, and so on, does little to distinguish among these different types of dispute. But which types are involved in a given case of moral disagreement matters to getting clear about what is at stake and what constraints govern attempts to resolve it.

The disagreements which ECCs are characteristically supposed to admit are standardly regarded as either type (c) or type (d) disputes. ${ }^{35}$ This paper has been largely devoted to arguing that many disagreements of the sort that ECCs characteristically admit are disputes of type (a). But recall that I am not claiming that those disputes are uniquely of this type. No doubt essential contestability can also be manifested in disputes of

\footnotetext{
${ }^{35}$ Whether a given writer regards these disagreements as of type (c) or (d) will depend on which of the two concept-conception distinctions mentioned at the end of $\S 3$ the writer is using. Roberts (2013: 90) interprets the Rawls-Nozick debate over distributive justice as a type (c) debate precisely on these grounds.
} 
type (c) or (d). But this does nothing to make the central features (E2)(E4) of essential contestability unique to them in particular. If those features may arise in many different ways, corresponding to different kinds of disagreement, then essential contestability doesn't look like a unified phenomenon. This should make us worry about its usefulness in understanding disagreement.

In conclusion I want to note that essential contestability might be manifested also in disputes of type (b). Such metalinguistic disputes concerning what the meaning of a word is or should be can happen even with words whose meanings seem quite fixed, and irrespective of whether the word is semantically evaluative. To take simple examples, we might dispute whether the race horse Secretariat counts as an "athlete" or whether Pluto is a "planet" just as much as we might dispute whether waterboarding is "torture" or maximizing aggregate utility is "morally right". ${ }^{36}$ Such disputes might well (be able to) manifest (E2)-(E4). For instance, they seem to have the right kind of open texture. We might have all the relevant evidence, including the facts about Secretariat's speed, strength, and so on, and yet disagree about whether athlete can be correctly applied to Secretariat. The evidence wouldn't resolve our underlying differences concerning what sorts of creatures are deserving of which sorts of recognition and rewards.

It isn't clear whether terms like athlete or planet have the kind of internal complexity and multiple describability which (E2)-(E3) ascribe to ECCs. But it seems a safe bet that some will. For example, it seems plausible that ordinary people and social theorists alike typically have only a partial grasp of what they are talking about when they talk about complex phenomena like race and gender. If it isn't clear what features are crucial for distinguishing the kinds we speak of when we use terms like race and

\footnotetext{
${ }^{36}$ The Secretariat example is due to Ludlow (2008: 108). Plunkett and Sundell (forthcoming) discuss at length this kind of "character disagreements" concerning moral terms like torture and morally right. Disputes in biology about what concept of species to adopt, mentioned in $\S 3$, also seem to be of type (b). For instance, we might dispute whether to define species in terms of common ancestry and, if so, whether genes reflecting the action of selection have greater weight, and so on.
} 
gender, then it wouldn't be surprising if social kind terms turned out to exemplify features like (E2)-(E4). But according to one prominent approach to social kinds, part of the social theorist's job is to formulate and evaluate reinterpretations of the meanings of social kind terms, and this enterprise is best guided not only by past practice but also by present concerns, including considerations of social justice. ${ }^{37}$ Under this approach it would seem unsurprising if ECCs characteristically admitted type (b) disputes irrespective of whether they are semantically evaluative. ${ }^{38}$

Although this potential source of essential contestability hasn't been my topic in this paper, it is important and merits further study. My present point is narrower. If essential contestability as characterized by (E2)-(E4) can be a function of admitting disagreement over what the meaning of some expression is or should be, this would further support the main claim of this paper. The central features of essential contestability can be explained in more general terms that have nothing in particular to do with whether ECCs are semantically evaluative. Evaluative ECCs might, of course, turn out to have some distinctive features. (They will be evaluative, for one thing. And it might be significant if all major evaluative concepts turned out to be multidimensional.) But essential contestability as such neither helps to demarcate the evaluative from the non-evaluative nor otherwise sheds distinctive light on the evaluative in particular.

\footnotetext{
${ }^{37}$ For a summary of this general methodological approach as applied to the study of race and gender plus further references, see Haslanger (2012: 12-16).

${ }^{38}$ Even if considerations of social justice are one relevant factor in assigning meanings to terms like race and gender, this doesn't as such make these terms semantically evaluative. Social justice can play a role in assigning meanings without thereby going into meanings. This is analogous to the potential role of evaluative factors in metasemantics briefly mentioned in $\S 4$.
} 


\section{References}

Benbaji, Y. 2009. Parity, Intransitivity, and a Context-Sensitive Degree Analysis of Gradability, Australasian Journal of Philosophy 87/2: 31335.

Blackburn, S. 1992. Through Thick and Thin, Proceedings of the Aristotelian Society, suppl. vol. 66: 285-99.

Collier, D., F. Hilgado, and A. Maciaceanu 2006. Essentially Contested Concepts: Debates and Applications, Journal of Political Ideologies 11/3: 211-46.

Dancy, J. 1995. In Defense of Thick Concepts, Midwest Studies in Philosophy 20: 263-79.

Dworkin, R. 1978. Taking Rights Seriously, London: Duckworth.

Gallie, W. B. 1956. Essentially Contested Concepts, Proceedings of the Aristotelian Society 56: 167-98.

Gibson, S. 2004. The Problem of Abortion: Essentially Contested Concepts and Moral Autonomy, Bioethics 18/3: 221-33.

Glanzberg, M. 2007. Context, Content, and Relativism, Philosophical Studies 136: 1-29.

Grafstein, R. 1988. A Realist Foundation for Essentially Contested Political Concepts, The Western Political Quarterly 41: 9-28.

Gray, J. 1977. On the Contestability of Social and Political Concepts, Political Theory 5/3: 331-48.

Gray, J. 1983. Political Power, Social Theory, and Essential Contestability, in The Nature of Political Theory, ed. D. Miller and L. Siedentop, Oxford: Clarendon Press: 75-101.

Haslanger, S. 2012. Resisting Reality, Oxford: Oxford University Press.

Helm, B. W. 2002. Felt Evaluations: A Theory of Pleasure and Pain, American Philosophical Quarterly 39/1: 13-30.

Hurley, S. 1989. Natural Reasons, Oxford: Clarendon Press.

IASP (International Association for the Study of Pain) Task Force on Taxonomy 1994. Part III: Pain Terms: A Current List with Definitions and 
Notes on Usage, in Classification of Chronic Pain, 2nd edition, ed. H. Merskey and N. Bogduk, Seattle: IASP Press: 209-14.

Kaplan, D. 1989. Demonstratives, in Themes from Kaplan, ed. J. Almog, J. Perry, and H. Wettstein, Oxford: Oxford University Press: 481-563.

Kekes, J. 1977. Essentially Contested Concepts: A Reconsideration, Philosophy and Rhetoric 10/2: 71-89.

Kennedy, C. 2007. Vagueness and Grammar: The Semantics of Relative and Absolute Adjectives, Linguistics and Philosophy 30/1: 1-45.

Ludlow, P. 2008. Cheap Contextualism, Philosophical Issues 18: 104-29.

Lukes, S. 1974a. Relativism: Cognitive and Moral, Proceedings of the Aristotelian Society, suppl. vol. 48: 165-89.

Lukes, S. 1974b. Power: A Radical View, London: Macmillan.

Mason, A. 1990. On Explaining Political Disagreement: The Notion of an Essentially Contested Concept, Inquiry 33/1: 81-98.

Nelkin, N. 1994. Reconsidering Pain, Philosophical Psychology 7/3: 32543.

Plunkett, D. and T. Sundell forthcoming. Disagreement and the Semantics of Normative and Evaluative Terms, Philosophers' Imprint.

Rawls, J. 1971. A Theory of Justice, Cambridge, MA: Harvard University Press.

Reitan, E. 2001. Rape as an Essentially Contested Concept, Hypatia 16/2: 43-66.

Rhodes, M. 2000. Coercion: A Nonevaluative Approach, Amsterdam: Rodopi.

Roberts, D. 2013. It's Evaluation, Only Thicker, in Thick Concepts, ed. S. Kirchin, Oxford: Oxford University Press: 78-96.

Ruben, D.-H. 2010. W. B. Gallie and Essentially Contested Concepts, Philosophical Papers 39/2: 257-70.

Sassoon, G. W. 2013. A Typology of Multidimensional Adjectives, Journal of Semantics 30/3: 335-80.

Swanton, C. 1985. On the 'Essential Contestedness' of Political Concepts, Ethics 95/4: 811-27. 
Väyrynen, P. 2013. The Lewd, the Rude and the Nasty: A Study of Thick Concepts in Ethics, New York: Oxford University Press.

Waldron, J. 2002. Is the Rule of Law an Essentially Contested Concept (in Florida)?, Law and Philosophy 21/2: 137-64.

Wiggins, D. 1998. Needs, Values, Truth, 3rd edition, Oxford: Clarendon Press.

Wilson, R. A., ed, 1999. Species: New Interdisciplinary Essays, Cambridge, MA: MIT Press. 